\section{PERFORMANCE FEATURES OF THE SUNFLOWER SEEDS OIL AS A HYDRAULIC BIO FLUID UNDER VARIOUS NORMAL LOADS}

Mohammed Hassan Jabal*, Muhannad Zedan Khlefia, Israa S. Ahmed, Hind Dawood Salman

Department of Electromechanical Engineering. University of Technology, Baghdad, Iraq
Article history

Received

25 November 2018

Received in revised form

31 October 2019

Accepted

16 January 2020

Published online

27 February 2020

*Corresponding author 50124@votechnology.edu.iq

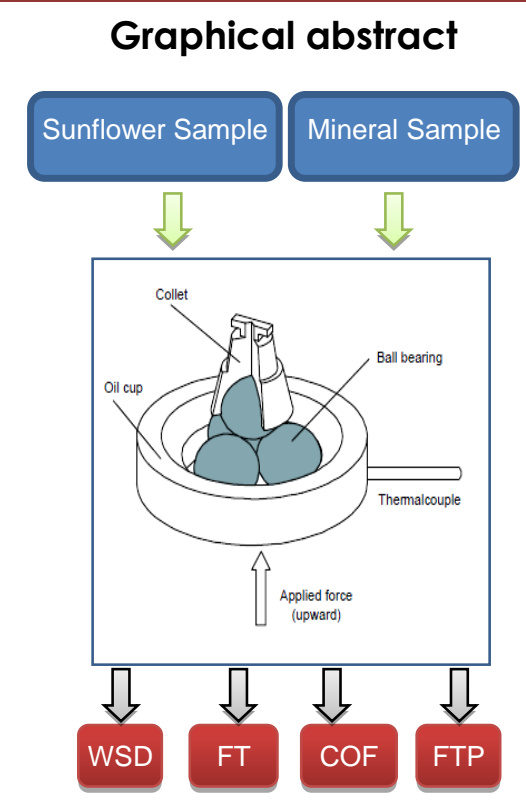

\begin{abstract}
Plant (vegetable) oils are renewable fluids. They have been developed to replace mineral-based fluids. Due to their distinguished features including ecofriendly properties and possibility of reducing the hydrocarbon and carbon dioxide emission when being used in the industrial processes or internal combustion (IC) engines, they are considered a sustainable source of biodegradable fluids. In this work, non-edible sunflower oil is investigated as a bio hydraulic fluid under various normal loads utilizing the four-ball tribotester. Considering the American Society for Testing and Materials (ASTM 4172-B) standard, all the experiments are conducted for different loads from $45 \mathrm{~kg}$ to 70 $\mathrm{kg}$, the balk temperature was increased until $75^{\circ} \mathrm{C}$, rotational speed to $1200 \mathrm{rpm}$ and every experiment was run for one hour. Compared with the mineral-based fluid sample, the outcomes shown that the sunflower oil possesses sufficient properties (anti-wear and anti-friction) especially under lower than $60 \mathrm{~kg}$ as a normal load. The results also shown that the sunflower oil is capable to be utilized as a hydraulic fluid.
\end{abstract}

Keywords: Hydraulic fluid, sunflower seeds oil, normal load, wear scar diameter

(C) 2020 Penerbit UTM Press. All rights reserved

\subsection{INTRODUCTION}

The base fluids for the mechanical, pneumatic and hydraulic systems can be classified to three main groups, including mineral-based oil or fluid, synthetic fluid and vegetable oil or fluid. Estimates of about 85 percentage of the base lubricant are usually manufactured from the crude petroleum [1]. In the same time, the plant or vegetable fluids, which are known as bio-fluids, are categorized into edible and non-edible fluids. Presently, high cost of predicting the synthetic work fluids and drooping of the petroleum stocks is leading to present the plant (vegetable) fluid as alternative to the mineral-based fluid for manufacture biodegradable lubricants. Eco- friendliness, increased availability, renewability and reasonable production cost are the major advantages of the vegetable oil, which attribute that adoption [2]. Until These days, many tribological characteristic studies were conducted on variety samples of the vegetable (plant) work fluids. For refining bleached and deodorized palm olein (RBD), a tribological characteristic was evaluated utilizing a four-ball tribotester. It was shown that the (RBD) palm olein has low value of frictions coefficients compared to the mineral oil. On the other hand, the wear diameter of ball bearing, which was lubricated with vegetable oil, presented larger value than of the sample of mineral lubricant [3]. Moreover, [4] via examining anti-wear performance of a coconut oil, It was found that the 
friction coefficient was reduced, while the diameter of the wear was increased at high temperatures. This is because of the presence of faity acids in the coconut oils.

The characteristics of the neat mustard seeds oil and blends of it with mineral-based oil were investigated according to the ASTM D4172-B standard, the results shown that the blending process of mineral oil with the mustard seeds oil caused a reduction in the wear diameter, coefficient of friction and increasing the value of the flash temperature parameter [5]. The studies of plant (vegetable) work fluids as a potential substitute for petroleum oils could be classified to four main series. The first series focused on the samples of neat plant oils, [6-7], while the second series deals with the vegetable-based oil emulsion [8]. the thired series tested the plant oil with additives [9], and the last (fourth)series concentrated on the features of the plant oil as an added ingredient [10-12]. The aim of current work is to study experimentaliy the performance features of the sunflower seeds oil as a source of biodegradable hydraulic bio fluid under various normal loads.

\subsection{METHODOLOGY}

\subsection{Apparatus}

To investigate and simulate the performance characteristics of the wear processes and friction for the fluid samples in this study, a four-ball wears tester (TR 30L, DUCOM) has been used, see Figure 1. The instrument is linked to data acqusition system in a laboratory computer. Locknut adaptor, ball-pot assembly, standard steel ball bearings and the collet are main parts of the tribotester, a four-ball machine as described by [13], utilizes new four balls, three balls are fixed at the bottom and the fourth ball at the top. The three-bottom balls are held strongly in a ball pot having $10 \mathrm{ml}$ oils that being tested and pressed against the top ball, which is made to rotate at the specific speed, while the three-bottom balls are pressed against the top ball [14].

This apparatus is capable to test collection of criterions according to the usage of the oil or fluid specimen. Anti-wear (ASTM D4172) and extreme pressure (ASTM D2596) are two main standards, which are used to investigate the fluid samples by four-ball tribotester. A diameter of the wear area (WSD), coefficient of the friction $(\mu)$, friction torque (FT) and flash temperature parameter (FTP) are the outputs data that are collected for all standard tests. Based on the ASTM 4172-B-standard test, the anti-wear and antifriction were investigated when exposing to various normal loads 45 to 70 step $5 \mathrm{~kg}$ during $60 \mathrm{~min}$ and rotational speed of the shaft is $1200 \mathrm{rpm}$. For the test temperature, the temperature of the tribotester heater was increased to $75^{\circ} \mathrm{C}$.

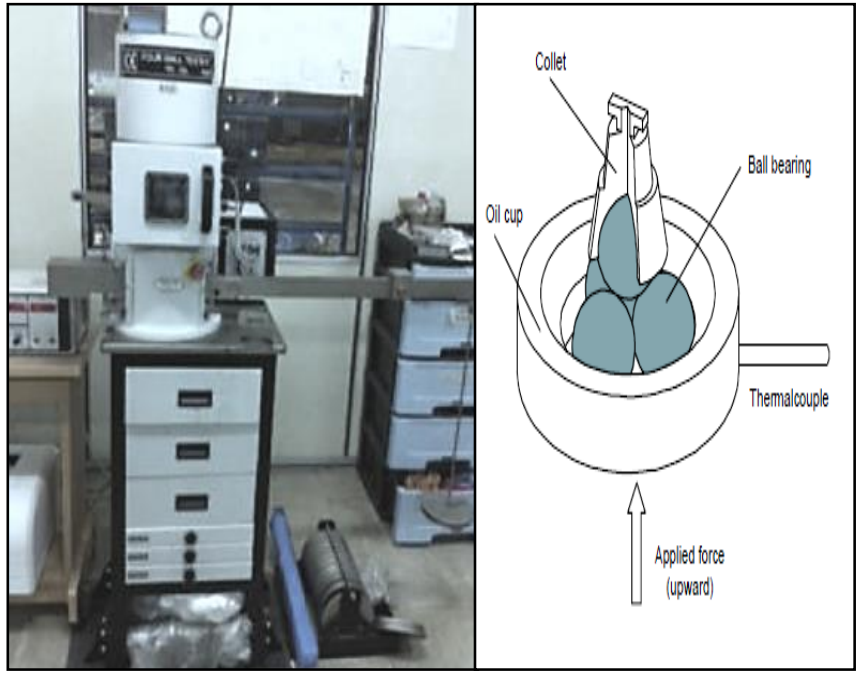

Figure 1 Four-ball wears tester

\subsection{Materials}

For each experiment in this study, four new standard ball bearing was used which made from chrome alloy steel (AISI E-52100), as specified in Table 1.

Table 1 Specifications of the ball bearing

\begin{tabular}{ll}
\hline Item & Specification \\
\hline Ball diameter $(\mathrm{mm})$ & 12.7 \\
\hline $\begin{array}{l}\text { Extra polish grade } \\
\text { (HRC) }\end{array}$ & 25 \\
\hline $\begin{array}{l}\text { chemical } \\
\text { composition }\end{array}$ & $\begin{array}{l}64-66 \\
\text { is a high carbon, chromium } \\
\text { containing low alloy steel } \\
\text { that is through hardening }\end{array}$ \\
\hline
\end{tabular}

\subsection{Working Fluids}

In this experimental work, oil of the sunflower seeds was used as a bio-hydraulic (vegetable oil). To be compared with investigation results, (mineral fluid-SAE 10 W-30 | was used as a sample of mineral-based fluid. For every test that had been onducted, $10 \mathrm{ml}$ of the fluid sample was utilized.

\subsection{Kinematic Viscosity}

Kinematic viscosity $\left(\mathrm{mm}^{2} / \mathrm{sec}\right)$ is a feature of fluid which represents the internal resistances of a fluid which get deformed by either the tensile stresses or the shear stresses of the fluid. It may be defined also, as an internal friction which occurs between the layers of fluid. For determining the Kinematic viscosity of the fluids samples at various temperatures a rotary viscometer was used, Figure 2. The viscometer has a spindle which is made from stainless steels and rotate at specific speed. When the spindle is inserted into 250 $\mathrm{ml}$ of oil sample, the fluid sample fluidity or kinematic 
viscosity is resisted by the speed of the spindle and this viscosity could be measured.

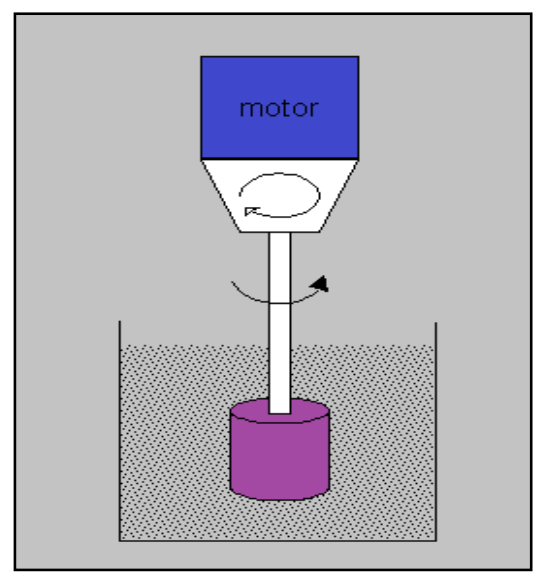

Figure 2 Front view of the rotary viscometer device

\subsection{Wear Scar Diameter (WSD)}

The measuring of the wear scar diameter (WSD) for each one of the three bottom balls was done after one hour of running to investigate the fluid characteristics of oil samples. The wear scar area was captured by the optical and scanning electronic microscope (under high resolution) connected to the computer software and the wear scar diameter could be measured from the micrographs that were captured. For reducing the error value of the wear scar diameter(which measured), the average value of the diameters for the three bottom balls was depended.

\subsection{Frictional Torque and Coefficient of Friction}

When start running of the four-ball tribotester machine, the frictional torque values were recorded by the data acquisition system during one hour of the test time. for all samples of fluids, the frictional torque values has increased rapidly until the $300 \mathrm{sec}$ of the running time,then the friction torques data showed more stability and became in a steady-state condition. Mean value of the frictional torques values in the steady state range was depended. The calculating of coefficient of friction was done by using the average value of the frictional torque according to IP-239, as shown in Equation (1):

$$
\mu=\frac{T \cdot \sqrt{6}}{3 . W \cdot r}
$$

\subsection{Flash Temperature Parameter}

The flash temperature parameter - FTP is a number being used to indicate the critical temperature of flash(when the fluid will fail under specific condition). The flash temperature parameter exihbits fewer probabilities of fluid films to break down [6]. The high value of FTP indicates to better performances of the fluids. The flash temperature parameter (FTP) is estimated by utilizing Equation (2):

$$
F T P=\frac{W}{(W S D)^{1.4}}
$$

\subsection{RESULTS AND DISCUSSIONS}

The performance characteristics for the vegetable and mineral-based fluid samples which were adopted in the current work were evaluated and characterized by utilizing the four-ball machine compliance with a standard of ASTM D4172-B. The viscosity (kinematic), WSD, coefficient of friction, friction torque and the temperature parameter of flash were depended as comparison factors between the samples of fluids.

\subsection{Kinematic Viscosity}

The outcomes of the measured values of the kinematic viscosity for the vegetable and mineral fluid were plotted under different temperatures of $\left(25^{\circ} \mathrm{C}\right.$ to $100^{\circ} \mathrm{C}$ ) as comparison quantities for the fluid samples, which were illustrated in Figure 3.

According to the figure, the kinematic viscosity values of both samples (sunflower seeds and mineralbased fluid) were reduced when the fluid temperatures was increased. The same outcomes in reducing of the kinematic viscosity values were gained from rising temperature by Golshokouh et al. [15].

At $100^{\circ} \mathrm{C}$ (high temperature of fluid), the viscosity values for all fluids sampls were compared to one another. Based on the results in Figure 3 , it could be concluded that the viscosity value of the mineralbased fluid was higher than that on sunflower oil (12.14 and $11.11 \mathrm{~mm}^{2} / \mathrm{sec}$ respectively). Additionally, at $40^{\circ} \mathrm{C}$ the kinematic viscosity for the fluid samples was (54.16 and $46.18 \mathrm{~mm}^{2} / \mathrm{sec}$ for the mineral-based and sunflower seeds fluid respectively). On another hand, it could be estimated that, index of viscosity for the sunflower seeds oil is higher than that of the mineral sample.

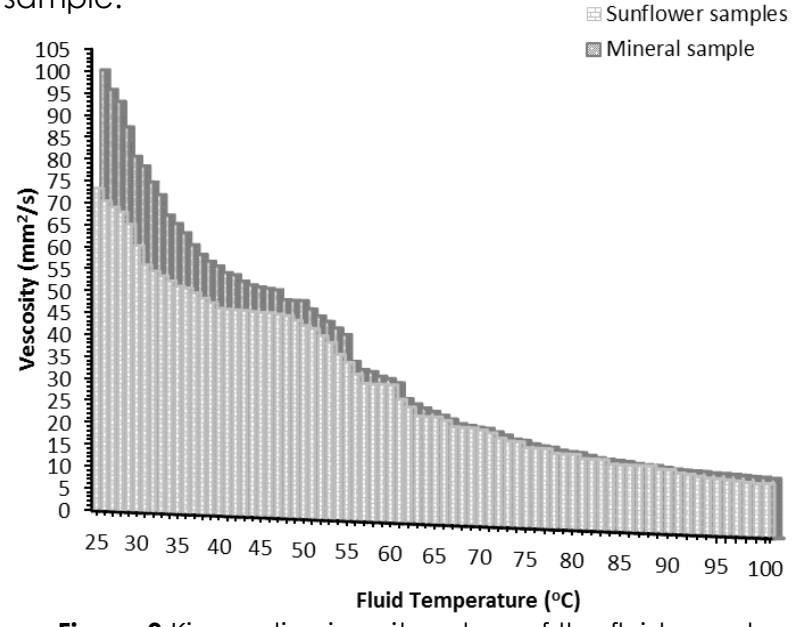

Figure 3 Kinematic viscosity values of the fluid samples 


\subsection{Wear Scar Diameter}

High resolution and optical scanning electron microscope (magnification 50X) was used to measure the diameter of the wear scar and study the characteristics of the wear area on the three bottom ball bearings after the experiments of the four ball tribotester were completed. The captured pictures through the optical microscopes were used to measure the diameter of the wear scars, and the average value was calcuated. By using the ASTM D4172-B standard, the wear was measured.

Figure 4 and Figure 5 show the comparison of (WSD) between the values of the sunflower seeds fluid and mineral engine hydraulic when being exposed to various loads $(45-75 \mathrm{~kg})$. From these figures, it could noted the positive correlation between the increase of the wear area diameter and the applied normal loads. At low loadings $(45,50$ and $55 \mathrm{~kg})$, the diameters of the sunflower fluids wear scar $(397,425$ and $427 \mu \mathrm{m}$ respectively) were found to be less than the diameters of the mineral engine hydraulic sample (413, 428 and $430 \mu \mathrm{m}$ respectively). The figures show also, under high loads $60 \mathrm{~kg}-70 \mathrm{~kg}$, the samples of the mineral-based fluid demonstrated better anti-wearing performance compared to the vegetable oil samples (sunflower). Such behavior occurs because the soap film of metallic was rubbed away during sliding under high load [16-18]. Therefore, it could be concluded that under low normal load, the sunflower seeds fluid exhibited superior anti-wearing efficiency in comparison to the mineral sample.

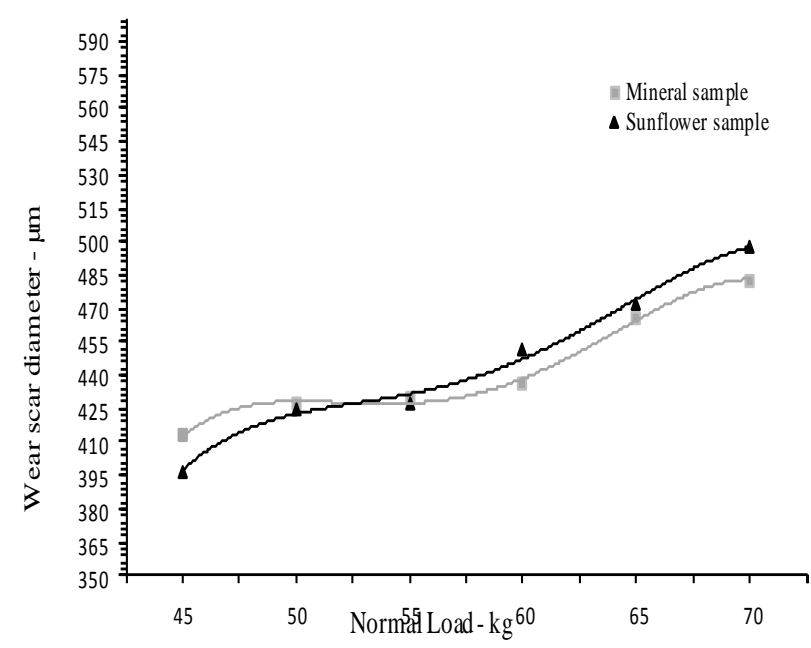

Figure 4 Wear scar diameter of the fluid samples when exposed to various loads
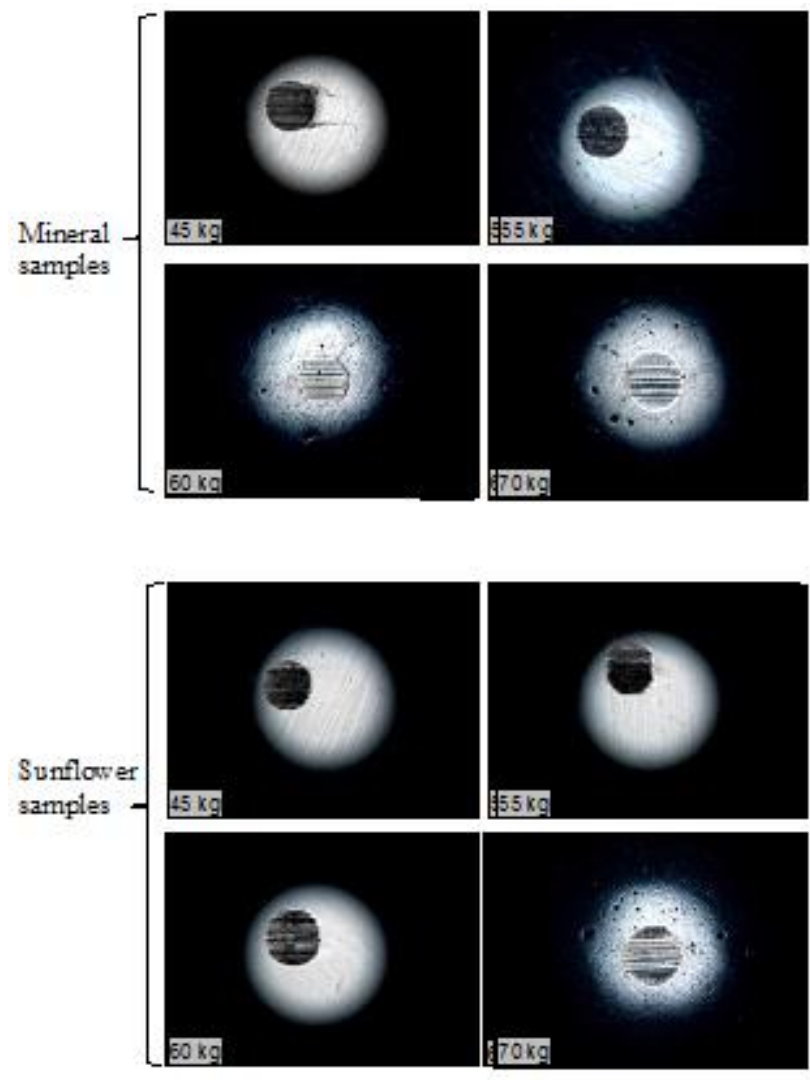

Figure 5 Optical micrographs for the fluid samples when exposed to various loads

\subsection{Friction Torque}

To investigate the anti-friction characteristic of the fluid samples (sunflower and mineral working fluid) when being exposed to various loads (45-70 kg step-5), the experiment conditions were adjusted to keep the bulk oil temperature at $75^{\circ} \mathrm{C}$, rotational speed at $1200 \mathrm{rpm}$ for one hour. In the Figure 6, the outcomes of the friction torque tests are shown. Based on the results in this figure it could be noted, with an increasing in the normal loads, the values of the friction torque were increased, and there was a direct correlation between the friction torque and the applying loads for the all fluids samples, because of the lubricant film breakdown, this leaded to a rise in the metal-to-metal contact, while creating high friction during the motion [7]. Additionally, the figure indicates the frictional torque for the sunflower seeds fluid results in low values compared to the mineral-based hydraulic under various loads. 


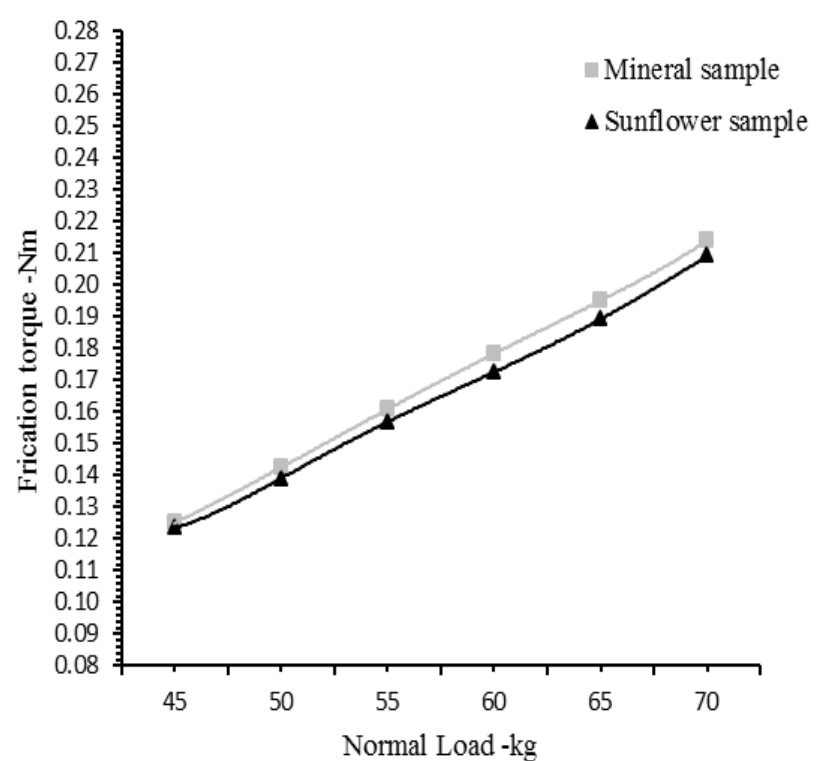

Figure 6 Friction torque of the fluid samples under various loads

\subsection{Friction Coefficient}

The results of friction coefficients under various loads of the sunflower fluid and mineral engine hydraulic were calculated by applying Equation (1), these results were illustrated as graphics manner in Figure 7. The figure compared the friction coefficient quantities of the fluid samples. Depending on the results under various loads $(45-70 \mathrm{~kg})$, it was found that all tests for fluids exhibited an increase in the friction coefficeint with an increase in testing load.

Also, it could be observed that, for the sunflower vegetable fluid, the values of the friction coefficients were still less compared to mineral-based fluid at differnent loads. The results in Figure 7 are attributed to the fact that the bio-fluids especially the sunflower can act as a friction reducing factor and has an ability to retain its property.

\subsection{Flash Temperature Parameter (FTP)}

Equation (2) was used to calculate the amount of FTP under the influence of the normal loads for the mineral and vegetable samples, the outcomes for one hour test time are shown in Figure 8. According to the results in this figure when the applied loads are low 45 to 55 $\mathrm{kg}$, the highest amounts were those for the sunflower fluid compared with the amounts for the mineral hydraulic, which means, when the sunflower fluid is utilized as a bio-hydraulic, the probability of breakingdown of fluids film will be minimized with an increase in the lubrication performance in the comparison with other flud samples. With load higher than $55 \mathrm{~kg}$, the mineral test sample was showing higher amount of FTP than the value for the vegetable fluid, for example under $70 \mathrm{~kg}$ the flash temperature parameters were 193.90 and 185.77 of the mineral and sunflower fluid respectively. That refers to the fact that under low value of normal load, the vegetable fluid exhibited superior lubrication properties compared to other fluid samples.

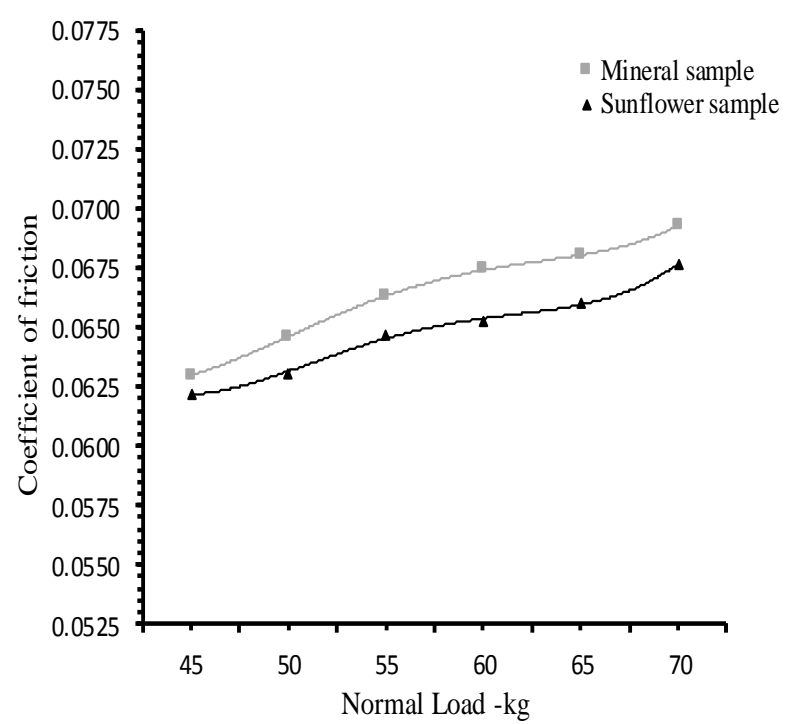

Figure 7 Coefficient of friction for the fluid samples under various loads

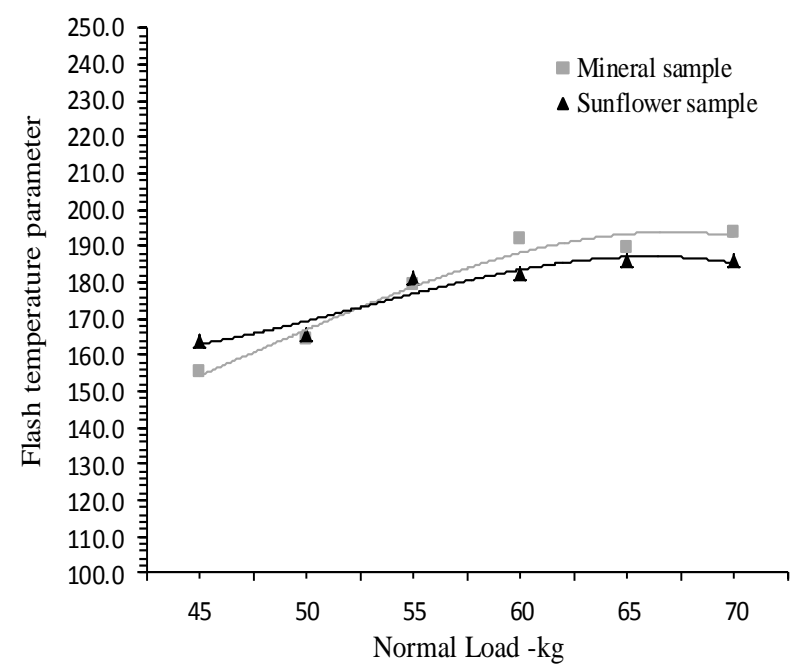

Figure 8 Flash temperature parameter for the fluid samples when exposed to various loads

\subsection{CONCLUSION}

According to the findings of this study, the following can be concluded; the lowest diameter of the wear area and highest temperature of the flash parameter for the sunflower fluid under $(45-55 \mathrm{~kg})$, indicate a better anti-wear performance under low normal loads.

Under various loads, the vegetable oil (sunflower seeds fluid) showed a lower value of friction torque and coefficient friction (good anti-friction behaviour) compared to the mineral-based fluid.

The overall analysis suggests that, under low loads, the sunflower seeds fluid have the possibility to become a renewable bio-hydraulic according to the better performance of lubricating and wear phenomena. 


\section{Nomenclatures}

FTP=flash temperature parameter $r=$ the distance between the hub and contact center on the balls is about $3.67 \mathrm{~mm}$

W=applied loads, $\mathrm{kg}$

$\mathrm{WSD}=$ wear scar diameter, $\mathrm{mm}$

$\mathrm{T}=$ friction torque, $\mathrm{kg} \mathrm{mm}$

$\mu=$ friction coefficient

\section{References}

[1] Yunus, R., Fakhru'L., Razi, A., Ooi, T. L., Omar, R., and Idris, A. 2005. Synthesis of Palm Oil Based Trimethylolpropane Esters with Improved Pour Points. Industrial and Engineering Chemistry Research. 44: 8178-8183.

[2] Delgado, M. A., Quinchia, L. A., Valencia, C., Franco, J. M. and Galegos, C. 2010. Viscosity Modification of Different Vegetable Oil with EVA Copolymer for Lubricant Applicants. Industrial Crops and Products. 32(3): 607-612.

[3] Ing, T. C., Rafiq, A. K. M., Azli, Y., and Syahrullail, S. 2012 Tribological Behaviour of Refined Bleached and Deodorized Palm Olein in Different Loads Using a Four-ball Tribotester. Scientia Iranica. 19(6): 1487-1492.

[4] Jayadas, N. H., Nair, K. P., and Ajithkumar, G. 2007. Tribological Evaluation of Coconut Oil as an Environmentfriendly Lubricant. Tribology International. 40(2): 350-354.

[5] Jabal, M., and Khalefa, M. 2018. Tribological Characteristics Evaluation of Mustard Oil Blends. Journal of Engineering. 24(3): 1-12.

[6] Maleque, M. A., and Masjuki, H. H. 1997, Investigation of the Anti-wear Characteristics of Palm Oil Methyl Ester Using a Four-ball Tribometer Test. Wear. 206: 179-186.

[7] M. Hassan et al. 2016. The Tribological Characteristics of RBD Palm Olein with Jatropha Oil Blend Using Four-ball Tribotester with Different Normal Loads. Applied Mechanics and Materials. 819: 499-503.

[8] Syahrullail, S., Zubil, B. M., Azwadi, C. S. N., and Ridzuan, M. J. M. 2011 . Experimental Evaluation of Palm Oil as Lubricant in Cold Forward Extrusion. International Journal of Mechanical Sciences. 53: 549-555.

[9] Jabal, M. H., Ani, F. N., and Syahrullail, S. 2014. The Tribological Characteristic of The Blends of RBD Palm Olein with Mineral Oil using Four-ball Tribotester. Journal Teknologi. 69(6): 11-14.

[10] Maleque, M. A., Masjuki, H. H., and Haseeb, A. S. M. A. 2000. Effect of Mechanical Factors on Tribological Properties of Palm Oil Methyl Ester Blended Lubricant. Wear. 239: 117-125.

[11] Dandan, M., Samion, S., Azman, N., Mohd Zawawi, F., Abdul Hamid, M. and Musa, M. 2019. Performance of Polymeric Viscosity Improver as Bio-lubricant Additives. International Journal of Structural Integrity. https://doi.org/10.1 108/IJSI-042019-0028.

[12] Azman, N., Samion, S., Moen, M., Abdul Hamid, M. and Musa, M. 2019. The Anti-wear and Extreme Pressure Performance of Cuo and Graphite Nanoparticles as an Additive in Palm Oil. International Journal of Structural Integrity. https://doi.org/10.1108/IJSI-03-2019-0026.

[13] Mohammed Hassan Jabal, Abdulmunem R. Abdulmunem \& Hussain Saad Abd. 2019. Experimental Investigation of Tribological Characteristics and Emissions with Nonedible Sunflower Oil as a Biolubricant. Journal of the Air \& Waste Management Association. 69(1): 109-118. DOI: 10.1080/10962247.2018.1523070.

[14] Fattah, F. N. A., Ariff, M. A. M., Hassan, J. M. and Nasir, A. F. 2017. The Tribological Characteristics of Rubber Seed Oil with Mineral Oil Blends. Malaysian Journal of Industrial Technology. 2(2): 17-22.

[15] Hassan, M., Ani, F. N., and Syahrullail, S. 2016. Tribological Performance of Refined, Bleached and Deodorised Palm Olein Blends Bio-lubricants. Journal of Oil Palm Research. 28(4): 510-519.

[16] Ahmed, H. I., Hassan, X. M., \& Abdul, C. A. 2011. Performance Changes for Window Type Air-conditioner Unit Chemically Treated to Work in an Industrial Petrochemical Environment. Engineering \&amp; Technology Journal. 29: 430-447.

[17] Jabal, M. H., Hassoun, E. O., Abdulmunem, A. R., \& Ani, F. N. 2019. Experimental Investigation of the Neat Rubber Seed Oil as a Hydraulic Fluid Using Four-Ball Tribotester. Journal of Engineering Science and Technology. 14(5): 2670-2680. 